\title{
Location Optimization Model for Hotels with Clustering Algorithm
}

\author{
Jian Chen ${ }^{\mathrm{a}}$, Jihong Yan ${ }^{\mathrm{b}}$ \\ School of Business and Management, Shanghai Polytechnic University, Shanghai 201209, China \\ achenjian@sspu.edu.cn; bjhyan@sspu.edu.cn
}

\begin{abstract}
In the hotel market, the most important issue is to pick a location, which means the location brings large portion of profit. On the other hand, different locations in a urban city area scale represent price tags. Along with a lot of "price war" in hotel industry, different hotels takes similar pricing strategy in order to win in the increasingly fierce competition, what kind of location is the right price to choose according to different price has become a major problem hotel managers must consider. This paper suggests a model to optimize the location for different scale hotels.
\end{abstract}

Keywords: Hotel industry; Location; Clustering Algorithm; Optimization.

\section{Background}

Pricing is a marketing strategy. In today's highly competitive and increasingly global market, pricing wise or not is often the key to the company to make a profit and losing money. Because of the complexity of pricing, many companies simply do not consider this issue, or to decide cost, according to the industry's traditional way of profit, or that the price is determined by the market, while they do not try to deal with them. Still others hold a different attitude, they will take the initiative as a key means of its pricing to achieve business objectives and financial goals. These smart pricing have recognized price with high leverage, and have been able to help improve the implementation of pricing according to the way the company profit and loss situation. Because the price theory that every enterprise must be an "optimum price", the "optimum price" includes the following meanings, that there must be a price you can create the most profitable; deviation "optimum price" farther, any error the price adjustment will bring adverse consequences; overpriced and too low will also bring adverse consequences. As the hotel there is a different location, target markets vary, room standard differences, providing services and customer demand for different seasons, hotel costs and competitive factors such as the complexity of the hotel room pricing may be more traditional industrial products and general services more complex, many hotels prices to determine the presence of a temporary, passive follow market prices, cannot take the initiative in accordance with market demand, supply and competition, referring to the hotel's business objectives and financial goals ahead of a decision optimal rates.

\section{Hotel industry pricing strategy and geographic analysis}

\subsection{China's hotel industry's market structure analysis}

Choosing the right pricing strategy on the premise that: the market structure of the industry in which to make the right judgments. According to the hotel industry-related economic statistical data analysis, the following basic judgments: 1 China's hotel industry is a monopolistic competitive industry, there are a lot of hotels and the consumer market, market concentration is close to zero; each hotel offers products and. other hotels in the products differ slightly. 2. From the viewpoint of market barriers, China's hotel industry performance as "easily into hard out" feature, capital threshold, technology and product differentiation, brand and sales network and other structural barriers to entry are very low, and the precipitate formed asset specificity costs, labor costs caused by placement of the hotel's high exit barriers. 3. On the monopolistic competition hotel industry, each hotel for the pricing of products have a certain control. Although the price of the product increased, but due to some consumer products for the hotel's special preference, they would still choose this hotel products.

\subsection{Beijing Hotels Geographical Distribution}

Use of the kernel k-means clustering algorithm to determine the two cluster centers. 
Judging from the coordinate: within 0-150 Yuan price range, hotel clusters in longitude within 116.145 to 116.681 longitude, latitude 39.719 to 40.087 inside, you can see the deep blue and green district occupied the vast region, respectively Xicheng, Haidian District, Chaoyang District, Tongzhou District, the cluster centers are as shown in Figure 1.

\begin{tabular}{llllllll}
\hline 1 & 1 & cluster_1 & 飘HOME)连钭 西城区 & 116.340 & 39.884 & 148 & 西城区 \\
7 & 7 & cluster_0 & 北京爱华宾馆 东城区 & 116.423 & 39.876 & 118 & 东城区
\end{tabular}

Figure 1. Cluster Center of Hotels from price 0 - 150

So, in the 0-150 Yuan price range, Xicheng District, occupied the center of the market, which is to say there is a lot or even an excess of small hotel.

By analyzing the upper left corner of the cluster, you can see the momentum of development and business opportunities in Yanqing County on a small hotel as shown in Figure 2.

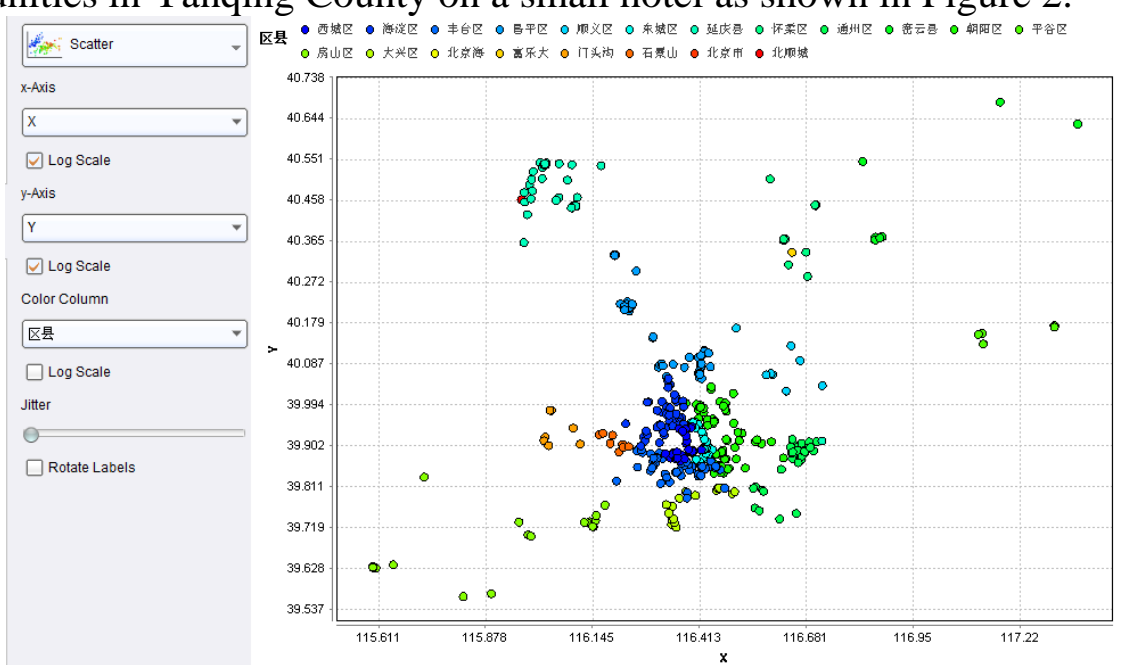

Figure 2. Diagram of distribution low price hotels

In the 151-300 price range, hotel clusters in longitude within 116.145 to 116.681 longitude, latitude 39.719 to 40.087 inside, you can see the deep blue and navy blue occupy a vast area of the county, respectively, Chaoyang District, Shunyi District Haidian District, the cluster centers are as shown in Figure 3 and Figure 4.

$\begin{array}{llllllll}7 & 7 & \text { cluster_0 } & \text { 北京旅居华伊 东城区北新棬 } 116.423 & 39.944 & 290 & \text { 东城区 } \\ 1 & 1 & \text { cluster_1 } & \text { 北京首都机坛顺义区国门商 } 116.589 & 40.067 & 130 & \text { 顺义区 }\end{array}$

Figure 3. Cluster Center of Hotels from price 150 - 300

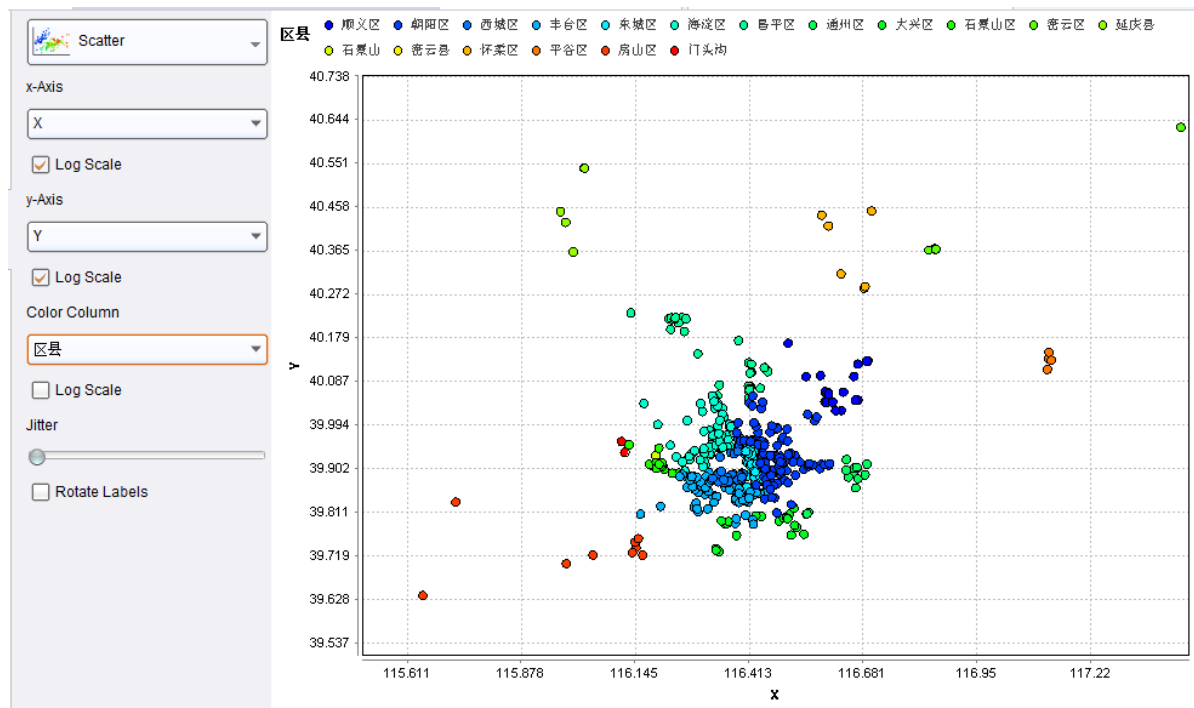

Figure 4. Diagram of distribution medium price hotels 
You can see from the figure, the distribution is more dense medium-sized hotel, away from the cluster center is closer, that is outside the scope of the development prospects of medium-sized hotel is not good.

\subsection{The Price of hotel distribution analysis}

From the relationship between the district and the price point of view: The price range within 0-350, gathered each region is relatively stable, basically in between 112-250 Yuan, every district are moving in this price range to move closer as shown in Figure 5.
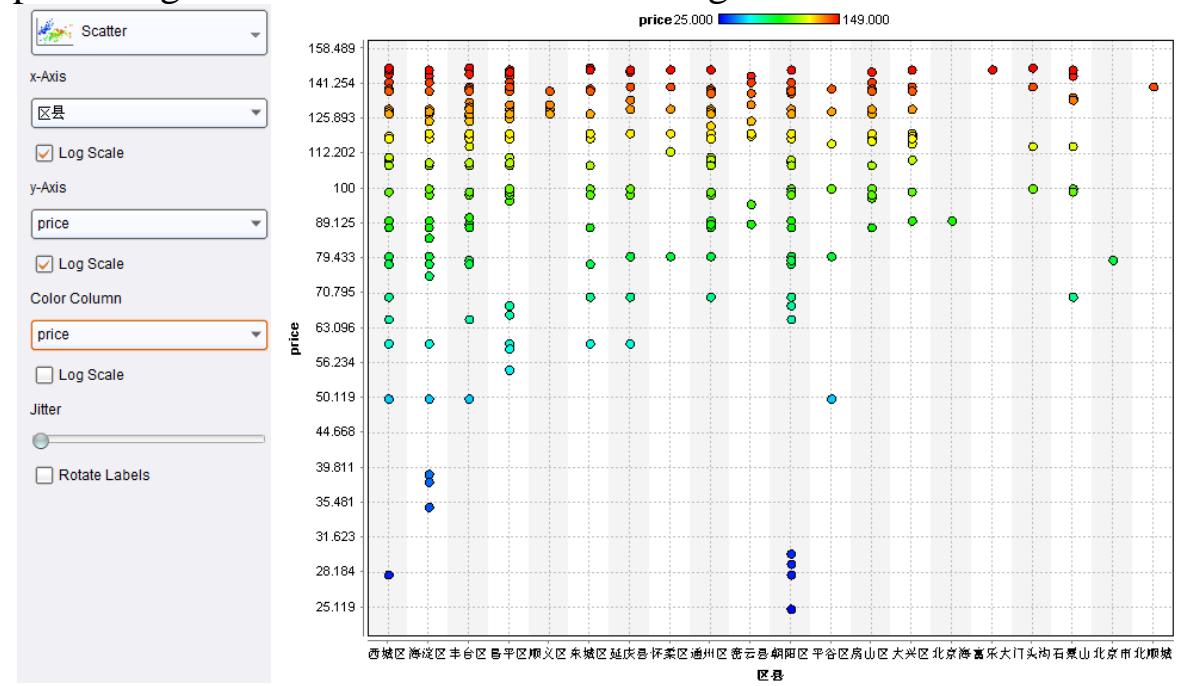

Figure 5. Stability of cheap and medium price hotels

\section{Conclusion}

The most active area in Beijing for hotel industry is Tongzhou and Yanqing District.

Tongzhou District, a cheap hotel (0-150 Yuan price range) distributed more, and there are a lot of medium-price hotel (151-300 Yuan price range), it can be seen that the rapid development of such level hotel in the area, and then Yanqing district there are many small hotels and a few medium-sized hotel, hotel development area have opportunities.

\section{Acknowledgments}

This paper is sponsored by Management Science and Engineering project of Shanghai Polytechnic University (No: XXKPY1606).

\section{References}

[1] Corigliano, M. A., \& Baggio, R. (2006). On the significance of tourism website evaluations. In M. Hitz, M. Sigala, \& J. Murphy (Eds.), Information and communication technologies in tourism (pp. 320-331). Wien, New York: Springer.

[2] Ho, C.-I., \& Lee, Y.-L. (2007). the development of an e-travel service quality scale. Tour Manage, 28(6), 1434-1449

[3] Jannach D, Lerche L, Gedikli F, Bonnin G (2013) what recommenders recommend: an analysis of accuracy, popularity, and sales diversity effects. In: Proceedings of the 21st International Conference on User Modeling, Adaptation and Personalization (UMAP 2013). Rome

[4] Leung, D., Law, R., van Hoof, H., \& Buhalis, D. (2013). Social media in tourism and hospitality: A literature review. Journal of Travel \& Tourism Marketing, 30(1/2), 3-22

[5] Manouselis N, Costopoulou C (2007) Analysis and classification of multi-criteria recommender systems. World Wide Web 10:415-441 